\title{
Prognostication of prostate cancer based on TOP2A protein and gene assessment: TOP2A in prostate cancer
}

Marina França de Resende1, Samantha Vieira', Ludmilla Thomé Domingos Chinen ${ }^{1}$, Francesco Chiappelli², Francisco Paulo da Fonseca', Gustavo Cardoso Guimarães ${ }^{3}$, Fernando Augusto Soares ${ }^{1}$, Ivan Neves ${ }^{1}$, Simone Pagotty ${ }^{1}$, Peter A Pellionisz ${ }^{2}$, Andre Barkhordarian², Xenia Brant ${ }^{1}$ and Rafael Malagoli Rocha ${ }^{1,4^{*}}$

\begin{abstract}
Background: TOP2A encodes for topoisomerase Ila, a nuclear enzyme that controls DNA topological structure and cell cycle progression. This enzyme is a marker of cell proliferation in normal and neoplastic tissues; however, little information is available about its expression in prostate cancer (PCa).

Methods: Immunohistochemistry (IHC) was automated using mouse monoclonal antibody against TOP2A (clone SWT3D1; DAKO, Carpenteria, CA, USA) at dilution 1:800 and Flex Plus detection system in autostainer 48Ultra (DAKO). FISH was performed using TOP2A (17q21)/ CEP17 probe kit (Kreateck Biotechnology, San Diego, CA, USA). Biochemical and pathological data from 193 patients with PCa were retrieved for the analysis, whose significance was considered when $p<0.05$. Also, fractal analysis was performed in a subset of 20 randomly selected cases.

Results: TOP2A protein expression correlated with higher Gleason scores and higher levels of preoperative PSA ( $p=0.018$ and $p=0.011$ ). Patients with higher levels of TOP2A presented shorter biochemical recurrence-free survival (BRFS) $(p=0.001)$. In multivariate analysis, we found that TOP2A remained an independent prognostic factor of BRFS, with a relative risk of $1.98(p=0.001 ; 95 \% \mathrm{Cl}, 1.338-2.93)$; thus, cases that expressed high levels of this enzyme had a shorter BRFS compared with TOP2A-negative or TOP2A-low cases. No alterations in TOP2A gene status nor correlation between FISH and IHC results were observed. Concerning fractal analysis, patients who expressed higher levels of TOP2A have angiolymphatic invasion and presented higher Gleason scores $(p=0.033$ and $p=0.025$, respectively). Also, patients with higher expression of TOP2A presented shorter BRFS $(p=0.001)$.

Conclusions: This is the first study to perform TOP2A protein and gene digital assessment and fractal analysis in association with BRFS in a large series of PCa. Also, we show that TOP2A gene copy number alterations are not observed in this type of tumor. So, higher protein expression of TOP2A is not related to gene amplification in PCa. Furthermore, TOP2A protein assessment has prognostic importance and, due to its relation with poor outcome, TOP2A IHC evaluation in the biopsy can represent an important tool for selecting the most suitable surgical and clinical approach for patients with PCa.
\end{abstract}

Keywords: FISH, Immunohistochemistry, Prostate cancer, TOP2A

\footnotetext{
* Correspondence: rafael.malagoli@gmail.com

'Department of Pathology, A. C. Camargo Cancer Hospital, Sao Paulo, Brazil

${ }^{4}$ Rua Professor Antônio Prudente 211, Liberdade São Paulo, SP 01509-900,

Brazil

Full list of author information is available at the end of the article
}

\section{Biomed Central}

(c) 2013 de Resende et al.; licensee BioMed Central Ltd. This is an Open Access article distributed under the terms of the Creative Commons Attribution License (http://creativecommons.org/licenses/by/2.0), which permits unrestricted use, distribution, and reproduction in any medium, provided the original work is properly cited. 


\section{Introduction}

Two homologous but distinct isoforms of type II human topoisomerases have been identified: the 1531 amino acid $170 \mathrm{kDa}$ DNA topoisomerase II $\alpha$ (TOP2A) and the 1621 amino acid $180 \mathrm{kDa}$ DNA topoisomerase II $\beta$ (TOP2B) encoded by the highly related TOP $2 A$ and $T O P 2 B$ genes, respectively $[1,2]$. TOP2A plays important roles in DNA synthesis and transcription, as well as chromosomal segregation during mitosis [1]. Beyond its physiological functions, TOP2A is reported to be a sensitive and specific marker of actively proliferating cells (in the late $S, G_{2}$ and $M$-phases of the cell cycle), which suggests the importance of its investigation in cancer [1].

Among men, cancer of the prostate, lung and bronchus, and colorectum accounted for $52 \%$ of all newly diagnosed cancers in 2010 [3]. Generally, prostate cancer (PCa) alone accounts for $28 \%(217,730)$ of incident cases in men [3]. This disease exhibits considerable variability in clinical behavior [4]. Many (if not most) PCa are clinically indolent, while others are clinically aggressive, becoming metastatic and lethal [4]. For localized PCa, treatment options range from active surveillance to decisive surgical excision (radical prostatectomy) or radiation therapy [4]. Increasingly, there is a need for prognostic biomarkers to accurately stratify patients for appropriate risk-adapted therapy [4]. TOP2A is clearly a proliferation marker and proliferation measurements in PCa have repeatedly been shown to provide prognostic information [4-11]. However, little information is available about TOP2A expression in prostate carcinoma [6].

In the present study we showed the prognostic importance of TOP2A in PCa by correlating immunohistochemical (IHC) and fluorescent in situ hybridization (FISH) with well-established prognostic values in $\mathrm{PCa}$ and with patients' biochemical and pathological data and biochemical recurrence-free survival (BRFS). To the best of our knowledge, this is the first study to perform TOP2A protein and gene digital assessment and fractal analysis in association with BRFS and other clinical data in a large series of PCa.

\section{Patients and methods}

Tumor samples and biochemical and pathological data Formalin-fixed paraffin-embedded tissue specimens from patients with $\mathrm{PCa}$ who underwent radical prostatectomy and were diagnosed at A.C. Camargo Cancer Hospital (Sao Paulo, Brazil) between 1991 and 2009 were retrieved for the study. As a result, a tissue microarray (TMA) containing 193 prostatic adenocarcinomas was constructed. Inclusion criteria were the availability of suitable paraffin blocks for IHC and follow-up information.

All PCa were graded based on the Gleason system by 2 independent pathologists at A.C. Camargo Cancer Hospital in a blind and consecutive manner to ensure adequate diagnosis and grade. The TNM staging system was used to describe the extent of $\mathrm{PCa}$ in patients (based on the AJCC Cancer Staging Manual, Seventh Edition, 2010, Springer New York, Inc.). TNM stages IIA and IIB were considered TNM stage II. All samples in this study were collected prior to hormone treatment or radiotherapy. The following biochemical and pathological parameters were recorded: preoperative PSA, Gleason score, TNM stage, lymph node status, angiolymphatic invasion, extraprostatic extension, margin status and seminal vesicle (SV) invasion. The study was approved by the ethics committee of our institution (Research Ethics Committee of A. C. Camargo Cancer Hospital) under process number $1473 / 10$.

\section{Tissue microarray construction}

Representative areas of prostatic adenocarcinoma were marked on hematoxylin- and-eosin-stained sections and cylinders $1 \mathrm{~mm}$ in diameter were punched from selected areas of the donor paraffin blocks (Beecher Instruments, Silver Spring, MD, USA). Each tumor was sampled twice in the TMA block that was cut $3 \mu \mathrm{m}$ thick for the IHC and FISH studies.

\section{Immunohistochemistry (IHC)}

IHC staining was performed using automated standard procedures (Flex Plus detection system, DAKO, Carpenteria, CA, USA) and mouse monoclonal antibody against TOP2A (SWT3D1 clone; DAKO, Carpenteria, CA, USA) at dilution 1:800. Specific standardized protocol supplied by the manufacturer was followed. Testis was used as positive control, and omission of primary antibody was applied as negative control.

\section{Immunohistochemical analysis}

All slides were digitalized using Aperio System (Vista, CA, USA), and the images provided by the software were exhibited on an LCD monitor under contrast, focus, saturation, and white balance standardization. Automated image quantification was performed using the nuclei quantification algorithm, which associates staining intensity with percentage of stained cells and generates a final score ranging from 0 (negative) to 1 (weak positive), 2 (moderate positive), or 3 (strong positive). Then, numerical scores were exported to a Microsoft Excel (Seattle, WA, USA) file for further statistical analysis.

\section{Fluorescent In situ Hybridization (FISH)}

FISH was performed using TOP2A (17q21)/CEP17 probe kit (Kreateck Biotechnology USA Inc, San Diego, CA, USA) and DAPI counterstaining. Fluorescent slides were assessed in a fluorescent microscope concerning chromosome 17 polyssomy and TOP $2 A$ gene amplification or deletion. 


\section{Fractal analysis}

$20 \mathrm{PCa}$ samples were randomly selected from our set to perform the fractal analysis. The histochemically stained cells were selected for capturing images and target stained cells were microphotographed in an isolated condition, with minimal contact or overlap of neighboring cells.

Cell images were captured with a Nikon D90 SLR digital camera 12.9 mega pixels DX-format and a file format of JPEG with an image size of 1,424-4,288 connected to the photoport attachment of a Nikon diaphot 300 inverted phase contrast microscope. Cells were observed with a $10 \times / 20 \mathrm{~m}$ wide field adjustable eyepiece at $400 \times$ magnification. Original images were stored in a TIFF format from JPEG in order to perform a background color correction using Micrografix picture publisher 8 windows graphic software. The images were then imported into Adobe Photoshop version CS5 for Macintosh. From each image, the three most suitable histochemically stained cells for fractal analysis were chosen. These three chosen cells were then cropped out of their original images with a $65 \times 65$ pixel frame that was centered on the chosen stained cell. Utilizing the quick selection tool in Photoshop (with settings of 100\% hardness, $8 \%$ spacing, auto-enhance turned off, and a selection size of three pixels) secondary histochemically stained cells present in the targeted $65 \times 65$ pixel image were selected and cropped out, resulting in one stained cell per new created image without artifacts (i.e., fragments of other cells). Captured images were stored in BMP format, with a bit depth of 24, and were then binarized by the Benoit 1.3 fractal analysis software (TruSoft International Inc., St. Petersburg, FL) to calculate the fractal dimension of the cells.

For the fractal dimension calculation, box dimension was taken as an appropriate approximation of fractal dimension. In the present study due to the original JPEG dimensions and size of the cells, the box sizes were set at 65, and the fractal dimension was computed by using the Benoit software (TruSoft International Inc., St. Petersburg, FL).

\section{Statistical analysis}

Mann-Whitney test was used to calculate the correlation between numerical variables. $X^{2}$ test was used to evaluate differences in frequency of categorical-variable groups. Spearman's rank correlation was used to analyze the correlation between continuous variables. Kaplan-Meier and log-rank tests were used to evaluate survival rates before biochemical recurrence concerning expression of TOP2A with BRFS (based on the increase in PSA, defined as PSA level $>0.2 \mathrm{ng} / \mathrm{ml}$ ). The level of statistical significance was set to 0.05 for these tests. Statistical analyses were performed using SPSS, version 11.0 (USA).

\section{Results}

Patients and clinical data

102 patients $(52.84 \%)$ presented Gleason score of 6 , and the remaining 91 cases (47.16\%) presented Gleason score between 8-10. 95 patients (49.22\%) presented TNM stage II; 86 (44.55\%) presented stage III; and 8 patients (6.23\%) presented TNM stage IV. The median preoperative PSA level was $8.6 \mathrm{ng} / \mathrm{ml}$. Other clinicopathological features are summarized in Table 1.

Table 1 Characterization of the cohort of 193 prostate cancer samples

\begin{tabular}{cc}
\hline Characteristics & $\mathbf{n}(\%)$ \\
\hline Age (years) & \\
$<50$ & $11(5.69)$ \\
$50-70$ & $160(82.9)$ \\
$>70$ & $21(11.4)$ \\
Preoperative PSA (ng/ml) & \\
$<10$ & $114(60.6)$ \\
$10 \geq$ PSA $<20$ & $50(26.5)$ \\
$\geq 20$ & $24(12.9)$
\end{tabular}

TNM stage (pathologic)

॥

$95(49.2)$

III

86 (44.6)

IV

$8(6.23)$

Gleason score

$6(3+3)$

$102(52.8)$

$7(3+4)$

46 (23.8)

$7(4+3)$

19 (9.8)

$8-10$

26 (13.5)

Angiolymphatic invasion

Presence

44 (23.2)

Absence

$146(76.9)$

Extraprostatic extension

Presence

41 (21.7)

Absence

$148(78.3)$

Positive margin

Presence

68 (21.6)

Absence

$122(78.4)$

Seminal vesicle invasion

Presence

22 (11.6)

Absence

$168(88.4)$

Positive lymph node

Presence

10 (5.44)

Absence

$174(94.6)$

Biochemical recurrence

Presence

$115(60.5)$

Absence

75 (39.5) 
PCa patients who had higher Gleason scores $(p<0.001)$, higher TNM stages $(p<0.001)$, positive margin $(p=$ $0.002)$, SV $(p<0.001)$, angiolymphatic invasion $(p=0.019)$, and positive lymph nodes $(p=0.003)$ presented shorter BRFS. The median of BRFS in our set of PCa patients was 30.49 months, ranging from 0.3 to 108.88 months.

\section{IHC and FISH signals}

IHC sharp and specific nuclear staining for TOP2A was observed in tumor cells as shown in Figure 1. Orange signals for TOP $2 A$ gene and green signals for centromeric region of chromosome 17 were observed; however, no numerical alterations in TOP $2 A$ gene and chromosome 17 were noticed in any tumor sample (Figure 2).

\section{TOP2A and biochemical and pathological data}

Patients who expressed higher levels of TOP2A presented higher Gleason scores and higher levels of preoperative PSA ( $p=0.018$ and $p=0.011$, respectively). Also, patients with higher expression of TOP2A presented shorter BRFS $(p=0.001$; Figure 3$)$, as shown in Table 2. On the other hand, there was no difference between tumors with Gleason score $7(3+4)$ and tumors with Gleason score $7(4+3)$ concerning TOP2A IHC expression.

TOP2A remained as an independent prognostic factor for BRFS in the multivariate analysis, with a relative risk of 1.98 ( $p=0.001 ; 95 \% \mathrm{CI}, 1.338-2.93)$. Thus, cases that expressed higher TOP2A presented shorter BRFS compared with TOP2A-negative or TOP2A-lower cases. The presence of SV invasion (hazard ratio $=3.038 ; p<0.001$;
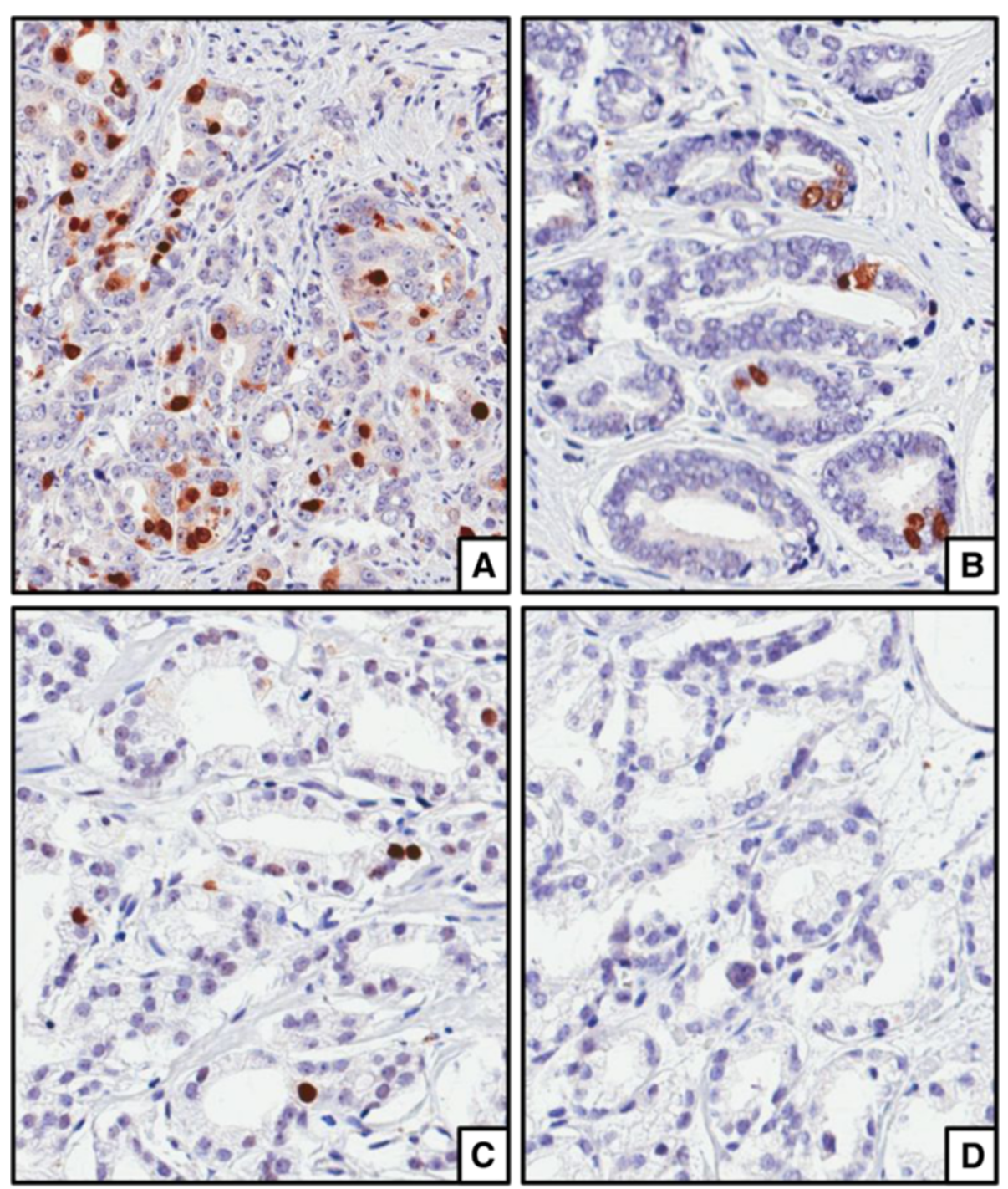

Figure 1 Immunostaining for TOP2A in prostate cancer observed at 200 magnification showing 3+ staining (A); 2+ staining (B); $1+$ staining (C); and negative staining (D). 


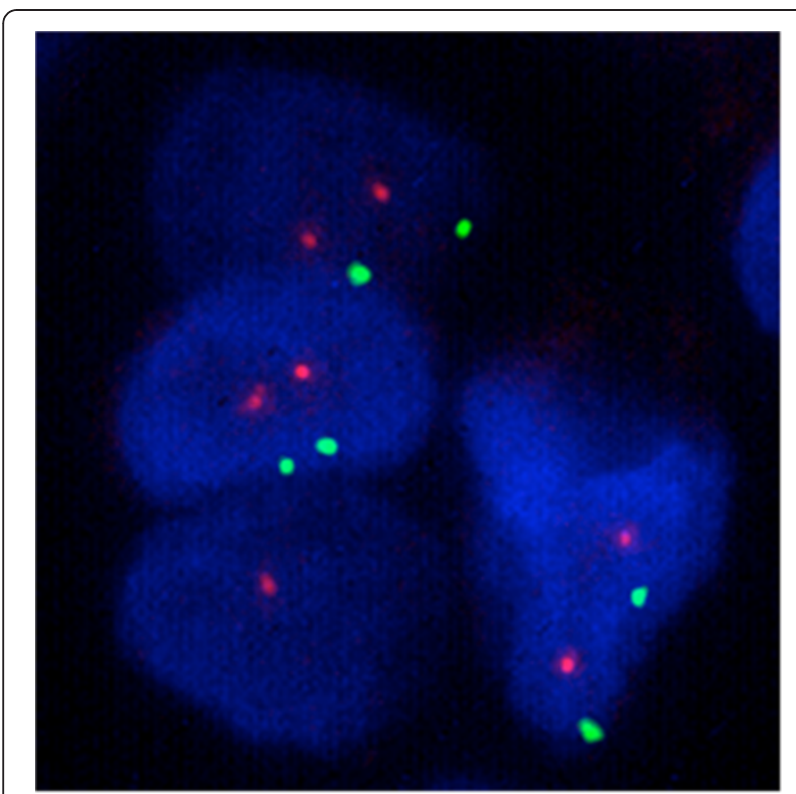

Figure 2 Examples of fluorescent in situ hybridization for TOP2A gene (orange) and chromosome 17 (green) showing no copy number alteration.
Table 2 Association between TOP2A expression and biochemical recurrence-free survival

\begin{tabular}{ccc}
\hline TOP2A intensity & Median (months) & $\boldsymbol{p}^{*}$ \\
\hline $1+$ (weak) & 60.230 & 0.001 \\
$2+$ (moderate) & 29.375 & \\
$3+$ (strong) & 16.743 & \\
\hline
\end{tabular}

* Statistically significant $p$ values inferior to 0.05 .

95\% CI, 1.755 - 5.256) also remained as an independent prognostic factor for BRFS (Table 3).

\section{Fractal analysis}

Median of TOP2A intensity evaluated in a subset of 20 randomly selected cases was 1.754 . Patients who expressed higher levels of TOP2A (TOP2A intensity $\geq 1.754$ ) presented angiolymphatic invasion and higher Gleason scores $(p=0.033$ and $p=0.025$, respectively). Also, patients with higher expression of TOP2A (TOP2A intensity $\geq 1.754)$ presented shorter BRFS $(p=0.001$; Figure 4).

\section{Discussion}

Analysis of the cell kinetics of cancer cells in situ (for example, by Ki-67 antigen expression or mitotic counts)

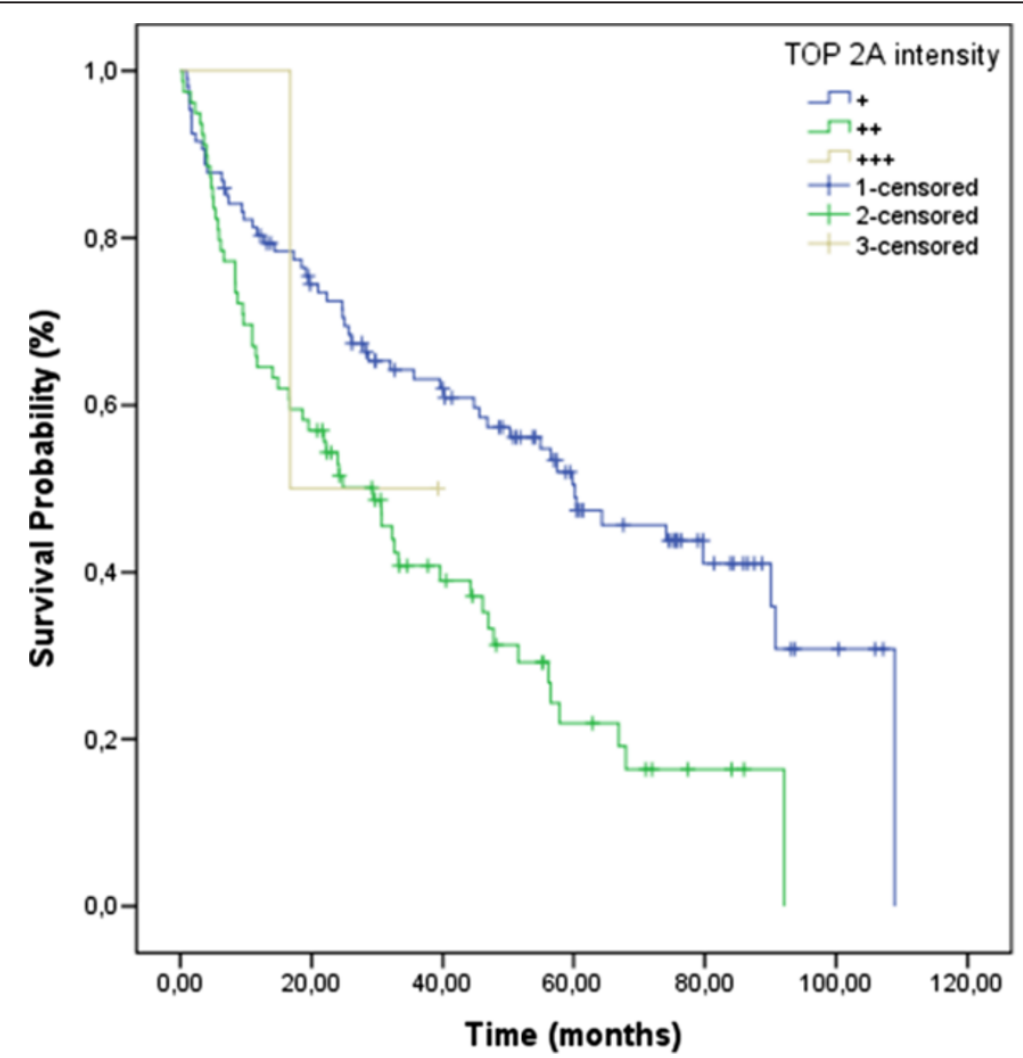

Figure 3 Biochemical recurrence-free survival curves showing lower survival rates of those cases which expressed high levels of TOP2A protein. 
Table 3 Multivariate analysis for biochemical recurrencefree survival

\begin{tabular}{cccc}
\hline Variables & $\begin{array}{c}\text { Hazard } \\
\text { ratio }\end{array}$ & $\mathbf{9 5 \% ~ C l}$ & $\boldsymbol{p}^{*}$ \\
\hline TOP2A (higher intensities) & 1.98 & $1.338-2.93$ & 0.001 \\
Seminal vesicle invasion (presence) & 3.038 & $1.755-5.256$ & $<0.001$ \\
\hline
\end{tabular}

* Statistically significant $p$ values inferior to 0.05 .

has been increasingly used to evaluate prognosis and/or biological behavior of various human malignancies [12]. TOP2A is a nuclear enzyme that controls DNA topological structure and cell cycle progression [13]. It mainly supports DNA decoiling, chromosome segregation during anaphase of the cell cycle, and DNA replication, by creating a DNA-linked protein gate through which another intact DNA duplex passes [14]. This enzyme is a marker of cell proliferation in normal and neoplastic tissues [15]. In malignant cells, overexpression of TOP2A protein might reflect not only the proliferative advantage of these cells, but also qualitative alterations caused by malignant transformation and dedifferentiation [12]. The IHC method for in situ determination of TOP2A has been extensively validated and shown to reflect closely the exact enzyme activity in formalin-fixed paraffin-embedded human tissues, leading to the prognostic and predictive importance of this test in other neoplasms [16].

This is the first study that brings together a gene and protein assessment of TOP2A in the largest series of prostate adenocarcinoma. Also, fractal image analysis was performed in order to confirm digital assessment in a subset of randomly selected cases. Furthermore, for the first time we bring an association between all these data and BRFS curve.

Concerning IHC pattern of expression for TOP2A, positive nuclear staining was found. Also, additional diffuse weak cytoplasmic staining was seen in some cases, as Faggad et al. [17] and Gotlieb et al. [18] also reported in their respective studies. Corroborating most works on literature, we found that the expression of TOP2A was an indicative of poor prognosis. Patients who expressed higher levels of its protein had higher Gleason scores, higher levels of preoperative PSA, and shorter BRFS. Indeed, high proliferation rates in cancers are typically associated with worse clinical outcome [4]. According to Faggad et al. [17], one explanation for the shorter survival rate associated with elevated TOP2A levels could be an enhancement of tumor cell proliferation, which results in increased tumor aggressiveness. In the

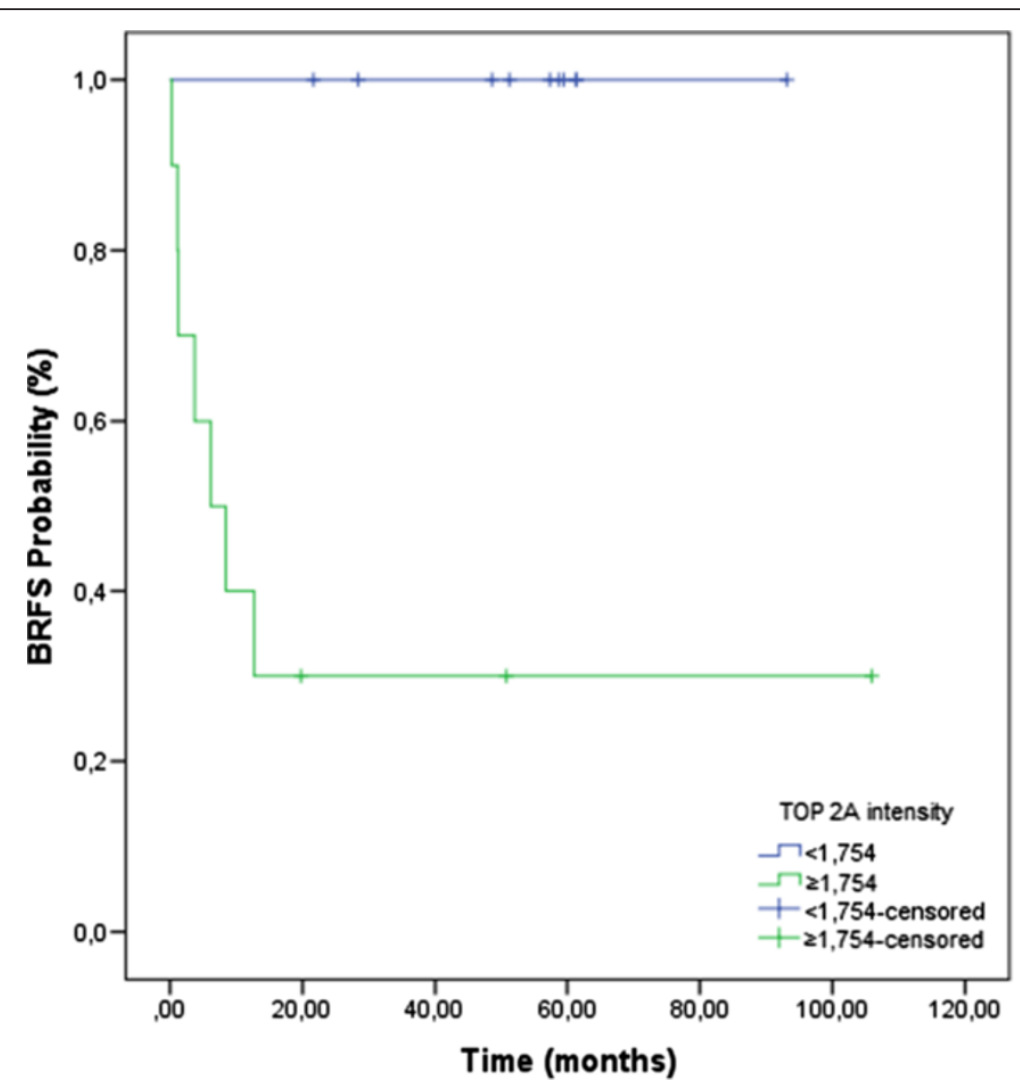

Figure 4 Biochemical recurrence-free survival curves concerning fractal analysis of a subset of 20 randomly selected cases showing lower survival rates of those who expressed higher levels of TOP2A protein. 
multivariate analysis, TOP2A positivity remained an independent prognostic factor for BRFS, along with the presence of SV invasion.

Increased TOP2A is a common, though not specific, occurrence in malignant cells [19]. According to O'Connor et al. [19], there are several mechanisms to explain this upregulation in these cells. First, both pRB and p53 are negative regulators of topoisomerase II $\alpha$, and both are well known to be inactivated or deleted in malignant cells [14]. Inactivated or deleted pRB or p53 would be expected to increase the expression of this enzyme [19]. Another possible mechanism for the overexpression of TOP2A is the amplification of a coding gene such as that for HER2/neu [19]. Both HER2/neu and TOP2A reside on the long arm of chromosome 17 and amplification of one gene locus could simultaneously overexpress both of these genes [19]. In the present study, we did not find any alterations on TOP2A status in FISH. Schindlbeck et al. [14] found that TOP2A amplification was not significant for outcome in women with primary breast cancer, protein expression only (IHC) was related to outcome in those patients. According to this work, protein expression might be more relevant than TOP $2 A$ amplification or deletion in predicting the outcome of breast cancer patients that received anthracycline-based chemotherapy [14]. In another study of our group [20], TOP2A amplification did not correlate with FISH results in soft tissue sarcomas. According to Werneck et al. [20], increased TOP2A expression does not appear to result solely from gene amplification. The explanation for this finding is still unclear; it might be due to posttranscriptional regulation [20]. This corroborates studies on other solid tumors, like breast cancer [21,22] and gastric carcinoma [23]. Werneck et al. [20] suggested that gene amplification and protein expression should be evaluated separately when the prognostic or predictive value of TOP2A is examined in any neoplasia.

High levels of TOP2A expression are generally associated with high levels of cellular proliferation and poor histologic differentiation of tumors [24]. The relationship between overexpression of this enzyme and poor prognosis has been reported in different neoplasias, like breast cancer [19], urothelial bladder carcinoma [12], larynx cancer [15], bladder cancer [24], and ovarian cancer [17]. On the other hand, although most studies on literature correlates high levels of TOP2A expression with poorer survival rates and more aggressive tumors, there are studies showing the opposite. Bredel et al. [25] concluded that high expression of TOP2A and Ki-67 appeared to be associated with prolonged survival in glioblastoma patients. In a recent work, Schindlbeck et al. [14] showed that TOP2A IHC positivity predicted lower risk of metastases and death in breast cancer patients. Yan et al. [26] demonstrated that high TOP2A expression was correlated with better disease-free survival for postoperative non-small cell lung cancer (NSCLC) patients who received adjuvant chemotherapy. One reason for these discrepant results is that these patients received adjuvant chemotherapy and high grade tumors tend to present better response to this type of therapy. Yan et al. [26] postulated that adjuvant chemotherapy might overcome the adverse biology of cancers that expressed high levels of TOP2A protein. According to this latter work, NSCLC patients with high expression of the enzyme might be able to obtain more benefits from adjuvant chemotherapy than those with low expression, which emphasizes the predictive importance of TOP2A for such patients [26].

Proliferation measurements in $\mathrm{PCa}$ have generally been done by studying the Ki-67 molecule, which is present in actively cycling cells [5]. IHC for Ki-67 in PCa has been shown to have prognostic importance (tumors with high Ki-67 expression tend to have a poorer prognosis and high tumor Ki-67 value also appear to predict tumor recurrence after radical prostatectomy) [5]. Since TOP2A has been found to correlate well with Ki-67 in a number of human diseases, Willman et al. [5] suggested that similar prognostic information might be obtained by TOP2A IHC, with an advantage that the enzyme is the target of drugs being used for treating PCa patients. However, there are few works in the literature correlating TOP2A and clinicopathological parameters of PCa. Sullivan et al. [7] showed that the expression of this enzyme increased with both stage and grade, and advancing stage was the stronger predictor of TOP2A expression. Willman et al. [5] and Hasby et al. [8], in their respective works, demonstrated that the prostatic carcinomas with the highest expression of the enzyme were more poorly differentiated and had the highest Gleason scores. Hughes et al. [6] showed that TOP2A expression increased with increasing Gleason score and with hormone insensitivity. Murphy et al. [9] showed that increased TOP $2 A$ copy number was associated with adverse clinical features, including high Gleason score, high stage, androgen resistant, HER2 amplification, and decreased survival under multivariate analysis. In a recent study, Karnes et al. [10] demonstrated that the time for $\mathrm{PCa}$ patients to develop systemic progression (SP) was significantly associated with TOP2A protein expression: higher 5-year SP rates were observed in patients with higher protein levels of the enzyme. Ida et al. [11] showed that TOP2A protein expression was predictive of SP and death in PCa patients with Gleason score $\geq 7$ treated surgically, especially in PCa without ERG overexpression. Malhotra et al. [4] demonstrated that a trimarker proliferation index (which included Ki-67, TOP2A, and E2F1) provided improved prognostic performance in $\mathrm{PCa}$; it predicted biochemical recurrence after radical prostatectomy. 
Alenda et al. [27] showed that PCa patients with Gleason score $7(4+3)$ have higher chances of presenting biochemical recurrence compared to patients with Gleason score $7(3+4)$. In addition, they also showed that the primary Gleason pattern 4 remained as an independent prognostic factor for the occurrence of biochemical recurrence in $\mathrm{PCa}$ patients [27]. Although the clinical difference between patients from both groups of Gleason $7[(3+4)$ and $(4+$ $3)$ ] is largely known, we found no difference in TOP2A expression between them. We suppose that TOP2A may not be related (at least not by itself) to early stages of carcinogenesis and morphological undifferentiating, which may result in further aggressive tumor biological behavior. However, when analyzing all Gleason scores there was a significant difference in TOP2A expression, showing that this protein may come up in more discrepant lesions. Furthermore, the absolute relation between the presence of TOP2A in tumors of patients with biochemical recurrence is an evidence that this protein is related to late stages of tumor development.

Besides its important role as a proliferation marker, as shown above, TOP2A is also the molecular target of several chemotherapy agents, including anthracyclines such as doxorubicin and etoposide [19]. These cytotoxic agents bind the DNA topoisomerase II complex and inhibit the relegation of DNA [19]. This converts TOP2A into a physiologic toxin and introduces high levels of permanent double-stranded breaks, which are detected by proteins ensuring genomic integrity [28]. As a result of the activation of this machinery, the cells with abundant DNA breaks are eliminated by apoptosis [28]. The sensitivity or resistance of a malignant cell to these anti tumor drugs, also called topo II poisons, is proportional to the level of TOP2A expression [11,14]. In PCa, there are several phase II trials using etoposide or docetaxel in combination with other chemotherapy agents to treat androgen-sensitive metastatic prostate carcinoma and hormone-refractory $\mathrm{PCa}$, with promising results [29-31].

The biological behavior of PCa still challenges researchers and urologists. While some patients present indolent disease with no need for treatment, others present aggressive disease with inevitable progression. Therefore a good prognostic and predictive marker of adjuvant and target therapies would be of great utility. In this sense, TOP2A is emerging as an important molecular target for many anticancer drugs, and several experimental works have clearly showed that cellular sensitivity to this enzyme is dependent on its high levels [30]. In conclusion, we found that higher expression of TOP2A protein in PCa patients is a strong indicative of poor prognosis. Also, since TOP2A is a target for many anti-neoplastic drugs, the IHC evaluation of this marker in routine practice can be a powerful tool for selecting appropriately aggressive therapies (use of adjuvant chemotherapy), specific target therapies, and the most suitable surgery approach in order to improve outcome of patients with prostate cancer. Also, we show for the first time that TOP2A gene copy number alterations are not observed in this type of tumor. So, higher protein expression of TOP2A is not related to gene amplification in PCa. Furthermore, TOP2A protein assessment has prognostic importance and, due to its relation with poor outcome, TOP2A IHC evaluation in the biopsy can represent an important tool for selecting the most suitable surgical and clinical approach for patients with $\mathrm{PCa}$.

\section{Competing interests}

The authors have declared no conflicts of interest.

\section{Authors' contributions}

MFR wrote the manuscript and participated in the data analysis and interpretation. SV helped to draft the manuscript. LTDC performed the statistical analysis. FC, PAP, AB and XB performed the fractal analysis. FPF and GCG participated in the provision of study material or patients, and in the collection and assembly of data. FAS provided the financial support, provision of study material or patients and administrative support. IN and SP carried out the immunoassays. RMR participated in the conception and design, and in the data analysis and interpretation, provided the financial support and the final approval of manuscript. All authors read and approved the final manuscript.

\section{Acknowledgements}

We acknowledge Fundação de Amparo à Pesquisa do Estado de São Paulo (FAPESP).

\section{Author details}

'Department of Pathology, A. C. Camargo Cancer Hospital, Sao Paulo, Brazil. ${ }^{2}$ UCLA School of Dentistry, Los Angeles, CA, USA. ${ }^{3}$ Department of Urology, A. C. Camargo Cancer Hospital, Sao Paulo, Brazil. ${ }^{4}$ Rua Professor Antônio Prudente 211, Liberdade São Paulo, SP 01509-900, Brazil.

Received: 24 January 2013 Accepted: 30 January 2013

Published: 11 February 2013

\section{References}

1. Tsavaris N, Lazaris A, Kosmas C, Gouveris P, Kavantzas N, Kopterides P, Papathomas T, Agrogiannis G, Zorzos H, Kyriakou V, Patsouris E: Topoisomerase I and Ila protein expression in primary colorectal cancer and recurrences following 5 -fluorouracil-based adjuvant chemotherapy. Cancer Chemother Pharmacol 2009, 64:391-398.

2. Mirski SE, Bielawski JC, Cole SP: Identification of functional nuclear export sequences in human topoisomerase lla and $\beta$. Biochem Biophys Res Commun 2003, 306:905-911.

3. Jemal A, Siegel R, X J, Ward E: Cancer statistics, 2010. CA Cancer J Clin 2010, 60:277-300.

4. Malhotra S, Lapointe J, Salari K, Higgins JP, Ferrari M, Montgomery K, van de Rijn M, Brooks JD, Pollack JR: A Tri-Marker Proliferation Index Predicts Biochemical Recurrence after Surgery for Prostate Cancer. PLoS One 2011, 6:e20293.

5. Willman JH, Holden JA: Immunohistochemical Staining for DNA Topoisomerase II-Alpha in Benign, Premalignant Lesions of the Prostate. Prostate 2000, 42:280-286.

6. Hughes C, Murphy A, Martin C, Fox E, Ring M, Sheils O, Loftus B, O'Leary J: Topoisomerase II- $a$ expression increases with increasing Gleason score and with hormone insensitivity in prostate carcinoma. J Clin Pathol 2006, 59:721-724.

7. Sullivan GF, Amenta PS, Villanueva JD, Alvarez CJ, Yang JM, Hait WN: The Expression of Drug Resistance Gene Products during the Progression of Human Prostate Cancer. Clin Cancer Res 1998, 4:1393-1403.

8. Hasby EA, Saied EM: Immunohistochemical Expression of Topoisomerase II Alpha and Her-2/neu in Prostatic Carcinoma and Benign Prostatic Hyperplasia. J Egypt Natl Canc Inst 2008, 20:158-167. 
9. Murphy AJ, Hughes CA, Barrett C, Magee H, Loftus B, O'Leary JJ, Sheils O: Low-Level TOP2A Amplification in Prostate Cancer Is Associated with HER2 Duplication, Androgen Resistance, and Decreased Survival. Cancer Res 2007, 67:2893-2898.

10. Karnes RJ, Cheville JC, Ida CM, Sebo TJ, Nair AA, Tang H, Munz JM, Kosari F, Vasmatzis $\mathrm{G}$ : The ability of biomarkers to predict systemic progression in men with high-risk prostate cancer treated surgically is dependent on ERG status. Cancer Res 2010, 70:8994-9002.

11. Ida CM, Cheville JC, Karnes R: Topoisomerase Ila Protein Expression Is Predictive of Outcome in Gleason Score $\geq 7$ Prostate Cancer Patients Treated Surgically and Is Dependent on ERG Status. Mod Pathol 2010, 23:422A.

12. Nakopoulou L, Zervas A, Lazaris AC, Constantinides C, Stravodimos C, Davaris $P$, Dimopoulos C: Predictive value of topoisomerase lla immunostaining in urothelial bladder carcinoma. J Clin Pathol 2001, 54:309-313.

13. Albadine R, Wang W, Brownlee NA, Toubaji A, Billis A, Argani P, Epstein I, Garvin AJ, Cousi R, Schaeffer EM, Pavlovich C, Netto GJ: Topoisomerase II a status in renal medullary carcinoma: immuno-expression and gene copy alterations of a potential target therapy. J Urol 2009, 182:735-740.

14. Schindlbeck C, Mayr D, Olivier C, Rack B, Engelstaedter V, Jueckstock J, Jenderek C, Andergassen U, Jeschke U, Friese K: Topoisomerase Ila expression rather than gene amplification predicts responsiveness of adjuvant anthracycline-based chemotherapy in women with primary breast cancer. J Cancer Res Clin Oncol 2010, 136:1029-1037.

15. Shvero J, Koren R, Shvili I, Yaniv E, Sadov R, Hadar T: Expression of Human DNA topoisomerase ii-a in squamous cell carcinoma of the larynx and its correlation with clinicopathologic variables. Am J Clin Pathol 2008, 130:934-939.

16. Shamaa AA, Zyada MM, Wagner M, Awad SS, Osman MM, Abdel Azeem AA: The significance of Epstein Barr Virus (EBV) \& DNA Topoisomerase II alpha (DNA-Topo II alpha) immunoreactivity in normal oral mucosa, Oral Epithelial Dysplasia (OED) and Oral Squamous Cell Carcinoma (OSCC). Diagn Pathol 2008, 3:45.

17. Faggad A, Darb-Esfahani S, Wirtz R, Sinn B, Sehouli J, Könsgen D, Lage H, Weichert W, Noske A, Budczies J, Müller BM, Buckendahl AC, Röske A, Eldin Elwali N, Dietel M, Denkert C: Topoisomerase Ila mRNA and protein expression in ovarian carcinoma: correlation with clinicopathological factors and prognosis. Mod Pathol 2009, 22:579-588.

18. Gotlieb WH, Goldberg I, Weisz B, Davidson B, Novikov I, Kopolovic J, Ben-Baruch G: Topoisomerase II Immunostaining as a Prognostic Marker for Survival in Ovarian Cancer. Gynecol Oncol 2001, 82:99-104.

19. O'Connor JK, Hazard LJ, Avent JM, Lee RJ, Fischbach J, Gaffney DK: Topoisomerase II alpha expression correlates with diminished diseasefree survival in invasive breast cancer. Int J Radiat Oncol Biol Phys 2006, 65:1411-1415.

20. da Cunha IW, De Brot L, Carvalho KC, Rocha RM, Fregnani JH, Falzoni R, Ferreira Fde O, Aguiar S Jr, Lopes A, Muto NH, Reis LF, Soares FA, Vassallo J: Prognostication of Soft Tissue Sarcomas Based on Chromosome 17q Gene and Protein Status: Evaluation of TOP2A, HER-2/neu, and Survivin. Ann Surg Oncol 2011, 19:1790-1799.

21. Durbecq V, Desmed C, Paesmans M, Cardoso F, Di Leo A, Mano M, Rouas G, Leroy JY, Sotiriou C, Piccart M, Larsimont D: Correlation between topoisomerase-llalpha gene amplification and protein expression in HER-2 amplified breast cancer. Int J Oncol 2004, 25:1473-1479.

22. Mueller RE, Parkes RK, Andrulis I, O'Malley FP: Amplification of the TOP2A gene does not predict high levels of topoisomerase II alpha protein in human breast tumor samples. Genes Chromosomes Cancer 2004, 39:288-297.

23. Kanta SY, Yamane T, Dobashi Y, Mitsui F, Kono K, Ooi A: Topoisomerase Ilalpha gene amplification in gastric carcinomas: correlation with the HER2 gene. An immunohistochemical, immunoblotting, and multicolor fluorescence in situ hybridization study. Hum Pathol 2006, 37:1333-1343.

24. Kim EJ, Lee YS, Kim YJ, Kim MJ, Ha YS, Jeong P, Lee OJ, Kim WJ: Clinical Implications and Prognostic Values of Topoisomerase-II Alpha Expression in Primary Non-muscle-invasive Bladder Cancer. Urology 2010, 75:1516.e9-13.

25. Bredel M, Piribauer M, Marosi C, Birner P, Gatterbauer B, Fischer I, Ströbel T, Rössler K, Budka H, Hainfellner JA: High expression of DNA topoisomerase $\mathrm{Ila}$ and $\mathrm{Ki}-67$ antigen is associated with prolonged survival in glioblastoma patients. Eur J Cancer 2002, 38:1343-1347.
26. Yan S, Shun-Chang J, Li C, Jie L, Ya-Li L, Ling-Xiong W: Topoisomerase II alpha expression and the benefit of adjuvant chemotherapy for postoperative patients with non-small cell lung cancer. BMC Cancer 2010, 10:621.

27. Alenda O, Ploussard G, Mouracade P, Xylinas E, de la Taille A, Allory Y, Vordos D, Hoznek A, Abbou CC, Salomon L: Impact of the primary Gleason pattern on biochemical recurrence-free survival after radical prostatectomy: a single-center cohort of 1,248 patients with Gleason 7 tumors. World J Urol 2011, 29:671-676.

28. Di Leo A, Isola J: Topoisomerase lla as a Marker Predicting the Efficacy of Anthracyclines in Breast Cancer: Are We at the End of the Beginning? Clin Breast Cancer 2003, 4:179-186.

29. Spitaleri G, Matei DV, Curigliano G, Detti S, Verweij F, Zambito S, Scardino E, Rocco B, Nolè F, Ariu L, De Pas T, de Braud F, De Cobelli O: Phase II trial of estramustine phosphate and oral etoposide in patients with hormonerefractory prostate cancer. Ann Oncol 2009, 20:498-502.

30. Vaishampayan U, Fontana J, Du W, Hussain M: Phase II trial of estramustine and etoposide in androgen-sensitive metastatic prostate carcinoma. Am J Clin Oncol 2004, 27:550-554.

31. Fizazi K, Beuzeboc P, Lumbroso J, Haddad V, Massard C, Gross-Goupil M, Di Palma M, Escudier B, Theodore C, Loriot Y, Tournay E, Bouzy J, Laplanche A: Phase II trial of consolidation docetaxel and samarium-153 in patients with bone metastases from castration-resistant prostate cancer. J Clin Oncol 2009, 27:2429-2435.

doi:10.1186/1479-5876-11-36

Cite this article as: de Resende et al:: Prognostication of prostate cancer based on TOP2A protein and gene assessment: TOP2A in prostate cancer. Journal of Translational Medicine 2013 11:36.

\section{Submit your next manuscript to BioMed Central and take full advantage of:}

- Convenient online submission

- Thorough peer review

- No space constraints or color figure charges

- Immediate publication on acceptance

- Inclusion in PubMed, CAS, Scopus and Google Scholar

- Research which is freely available for redistribution

Submit your manuscript at www.biomedcentral.com/submit
C) Biomed Central 